\section{COVID-19 in Hemodialysis Patients}

Sir,

Patients on maintenance hemodialysis (HD) are commonly affected with multiple comorbidities and are also prone to infections due to uremia-induced suppressed immunity, making them more vulnerable to COVID-19., The altered immune state together with associated comorbidities and impractical social distancing due to inevitable frequent visits to dialysis unit poses threat of severe COVID-19. The risk may further increase in HD patients of low income countries due to lack of facilities and limitation of implementation of epidemiologic measures for infection control. Studies from various parts of the world have reported varying prevalence, clinical presentations and case fatalities. Prevalence ranging $2-28 \%$ with regional variations and a higher mortality rate $14-51 \%$ has been observed compared to general population. ${ }^{3-5}$ Moreover, the clinical presentation of COVID-19 may range from asymptomatic to non-specific symptoms that may be attributed to dialysis, such as shortness of breath or cough from fluid overload and; hence, poses challenge in prompt diagnosis of disease in this group. There is limited information on symptoms, laboratory and radiologic abnormalities and outcomes of COVID-19 in patients on HD from Pakistan.

We reviewed clinical presentation and short-term outcomes of COVID-19 in patients on HD at our centre. Out of 108 patients, $13.9 \%(n=15)$ were affected by COVID-19. Mean age was $62.8 \pm$ 8.6 years and $53.3 \%$ were females. Most common cause of kidney failure was diabetic kidney disease $(80 \% ; n=12)$, unknown etiology $(13.3 \%, n=2)$, chronic glomerulonephritis $(6.7 \%, n=1)$. Among comorbid conditions, hypertension was the most prevalent $(100 \%)$, followed by diabetes mellitus $(86.7 \%)$ and ischemic heartdisease (33.3\%). Onepatient had chronic obstructive pulmonary disease (COPD) and another had active malignancy; and was on chemotherapeutic treatment. Forty percent of the patients were asymptomatic. Among symptomatic patients, shortness of breath was commonest $(40 \% ; n=6)$, followed by cough $(26.7 \%$; $n=4)$ and fever $(20 \% ; n=3)$. Half of the patients required hospitalisation; and more than two-thirds of those required invasive or non-invasive ventilation. The mortality rate observed was $40 \%$. Compared to survivors, deceased patients were significantly older and had higher inflammatory markers including C-reactive protein, ferritin, procalcitonin, lactate dehydrogenase. Lymphopenia, a universal finding in COVID-19, was not observed; and only $40 \%$ patients had radiological findings consistent with COVID-19 at the time of presentation.

Given the high mortality rates, patients on maintenance HD are considered as a high-risk population for poor outcomes. A wideclinical presentation and asymptomatic nature of disease in some cases emphasise the need for high clinical suspicion as well as implementation of proactive measures in screening and isolating suspected cases. Effectively, prevention of the spread of infection among HD centres, healthcare personnel, and patients is essential to ensure the safety of all stakeholders as well as continued delivery of HD to patients.

\section{PATIENTS' CONSENT:}

Not applicable (All data were obtained from electronic and filebased medical records and the Institutional Review Board waived off the need for informed consent).

\section{CONFLICT OF INTEREST:}

The authors declared no conflict of interest.

\section{AUTHORS' CONTRIBUTION:}

SY: Conception and design, interpretation, critical revision, final approval.

AH: Data acquisition and analysis, interpretation, drafting, final approval.

ZN: Data acquisition and analysis.

\section{REFERENCES}

1. Saran R, Robinson B, Abbott KC, Agodoa LYC, Bhave N, Bragg-Gresham J, et al. US renal data system 2017 annual data report: Epidemiology of kidney disease in the united states. Am J Kidney Dis 2018; 71(3 Suppl 1): A7. doi: 10.1053/j.ajkd.2018.01.002.

2. Kato S, Chmielewski M, Honda H, Pecoits-Filho R, Matsuo S, Yuzawa $Y$, et al. Aspects of immune dysfunction in endstage renal disease. Clin J Am Soc Nephrol 2008; 3(5):1526-33. doi: 10.2215/CJN.00950208.

3. Xiong F, Tang $\mathrm{H}$, Liu L, Tu C, Tian JB, Lei CT, et al. Clinical characteristics of and medical interventions for COVID-19 in hemodialysis patients in Wuhan, China. J Am Soc Nephrol 2020; 31(7):1387-97. doi: 10.1681/ASN.2020030354.

4. Valeri AM, Robbins-Juarez SY, Stevens JS, Ahn W, Rao MK, Radhakrishnan J, et al. Presentation and outcomes of patients with ESKD and COVID-19. J Am Soc Nephrol 2020; 31(7):1409-15. doi: 10.1681/ASN.2020040470.

5. Fisher M, Yunes M, Mokrzycki MH, Golestaneh L, Alahiri E, Coco M. Chronic hemodialysis patients hospitalised with COVID-19-short-term outcomes in Bronx, New York. Kidney 360 2020; 1(8):755-62. doi.org/10.34067/KID.0003672020.

Sonia Yaqub, Amna Hamid and Zarghoona Naeem

Department of Medicine, Section of Nephrology, The Aga Khan University Hospital, Karachi, Pakistan

Correspondence to: Dr. Sonia Yaqub, Department of Medicine, The Aga Khan University Hospital, Stadium Road, Karachi, Pakistan

E-mail: sonia.yaqub@aku.edu

Received: January 07, 2021; Revised: May 30, 2021;

Accepted: June 07, 2021

DOI: https://doi.org/10.29271/jcpsp.2021.JCPSPCR.CR141 